\title{
The Changing Profile of The College of The Bahamas' Graduates
}

\author{
William J. Fielding \\ Jeannie Gibson \\ Planning Unit ${ }^{1}$
}

\section{ABSTRACT}

This paper uses graduation data to show the changes that have occurred in the profile of the College's graduates from 1976 to 2013. The data demonstrate the rise and fall in the number of graduates receiving Associate degrees. The decline in the number of graduates obtaining Associate degrees can be connected with the rise in the number of graduates receiving Baccalaureate degrees. While College to University: Strategic Plan, 2009-2019 (http://www.cob.edu.bs/Administration/StrategicPlan.pdf) of the College of The Bahamas considers the College era to be associated with two phases, "Creation and Early Growth: The College of The Bahamas, 1974-1995" and the "Transition Era: From College to University, 19952009"; the graduation data show a complex and ongoing picture of change, consolidation and change.

\section{INTRODUCTION}

In 1975, the College was a British-style sixth form college. British GCE (General Certificate of Education) A-levels (advanced level examinations typically taken by those seeking entrance to United Kingdom universities) were taught at the College as well as technical vocational subjects. In 1977 students graduated from programmes the levels of which are not clearly recorded; consequently these graduates are typically recorded as "unknown" with respect to their programmes. The graduation booklet of 1978 demonstrates the diverse nature of the programmes completed by students; they included diplomas in electronic and radio communications, as well as associate degrees in Business, and unspecified programmes in
Education. It is clear that the College then was not merely an academic institution, but a hybrid one which also taught technical and vocational subjects. Graduates in the technical and vocational areas are seen in the graduation booklets up until the early 1990s.

In 1980, students graduated with the University of the West Indies baccalaureate degree in Education. Although the programme was not a College of The Bahamas degree, it was taught at the College, and so these graduates represent a tangible outcome of the College's instruction and the programme characterizes a clear orientation towards academic programmes associated with that of a university. It was not until 1991 that the College started to teach its own

\footnotetext{
${ }^{1}$ William J. Fielding, Director of Planning and Jeannie Gibson, Planning Unit, The College of The Bahamas, P.O. Box N-4912, Nassau, Bahamas.

E-mail: william.fielding@cob.edu.bs

APA reference: Fielding, W. J., \& Gibson, J. (2014). The changing profile of College of The Bahamas's graduates. The International Journal of Bahamian Studies, 20(2), II 12-15. https://doi.org/10.15362/ijbs.v20i2.217
}

(c) W.J. Fielding \& J. Gibson, 2014. Journal compilation @ The International Journal of Bahamian Studies, 2014 
bdccalaureate-level programme. The emergence of baccalaureate degrees saw the phasing out of associate degrees. The model of the College teaching a third-party curriculum was followed at the master's level, again in the area of education, and these programmes were later followed by the College's offering of its own master's degrees in education and business.

Between 1976 and the May 2013 graduation, 14,888 students had completed programmes taught at the College as illustrated in Figure 1.

As the College entered the 21st century, associate degree programmes started to be phased out in favour of four-year programmes. This clearly had an impact on the number of graduates, as students had to remain at the College for a longer period before they could graduate. This could probably explain the decline in the graduate numbers in the early 2000s as seen in Figure 1.

The numbers of graduates in the different degree and certificate categories, spanning 1976 to 2013, are depicted in Figure 2.

Associated with the ever-changing assortment of programmes, have been changes in the size of the graduating classes. In part, these changes can be attributed to the College responding to national needs, providing training for different cohorts in order to address national skills shortages, for example in nursing and education. Notwithstanding short-term changes in the sizes of graduating classes, Figure 1 demonstrates an underlying increase in the graduating class size.

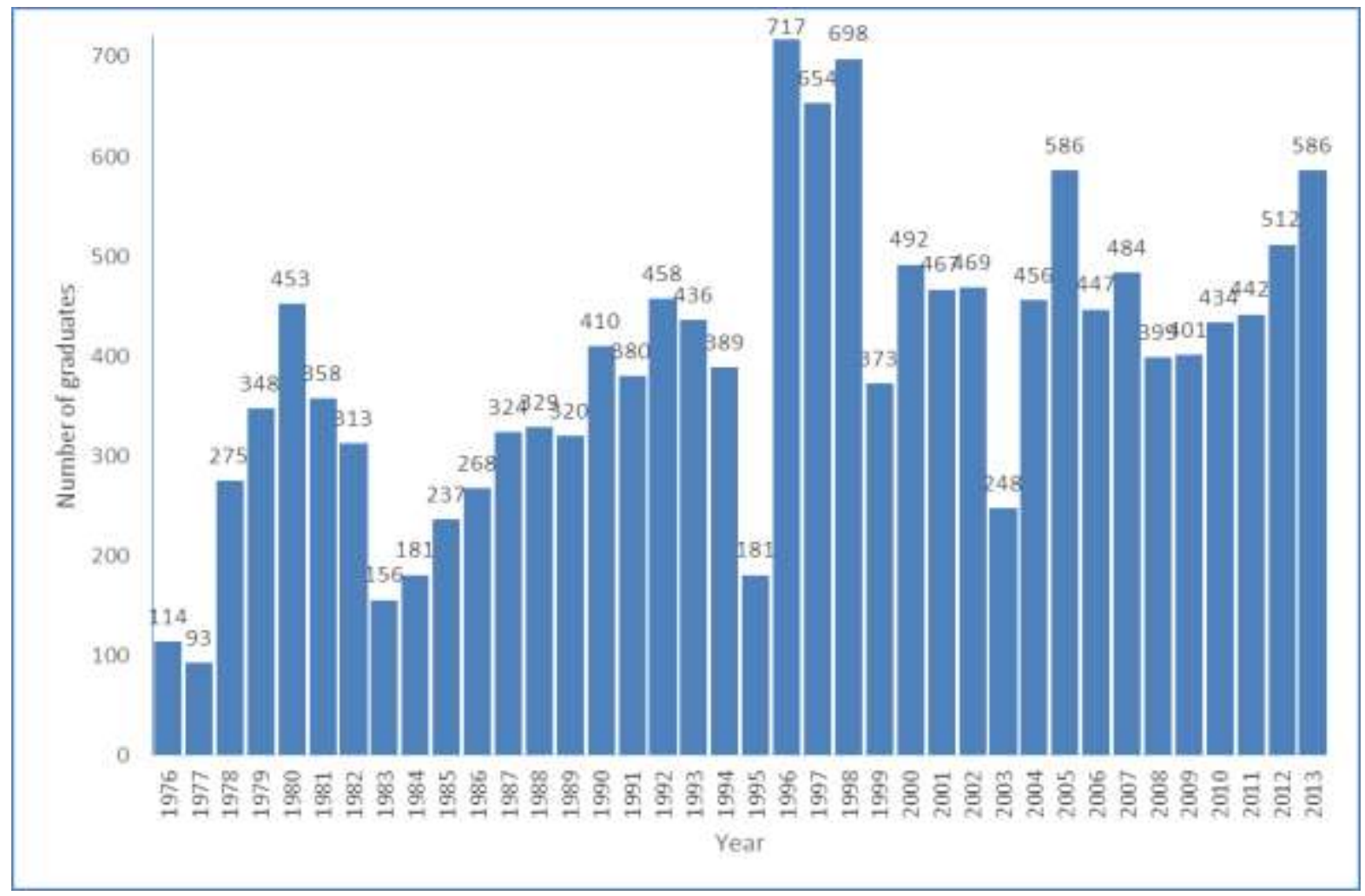

Figure 1: The number of students graduating at the end of each academic year. 


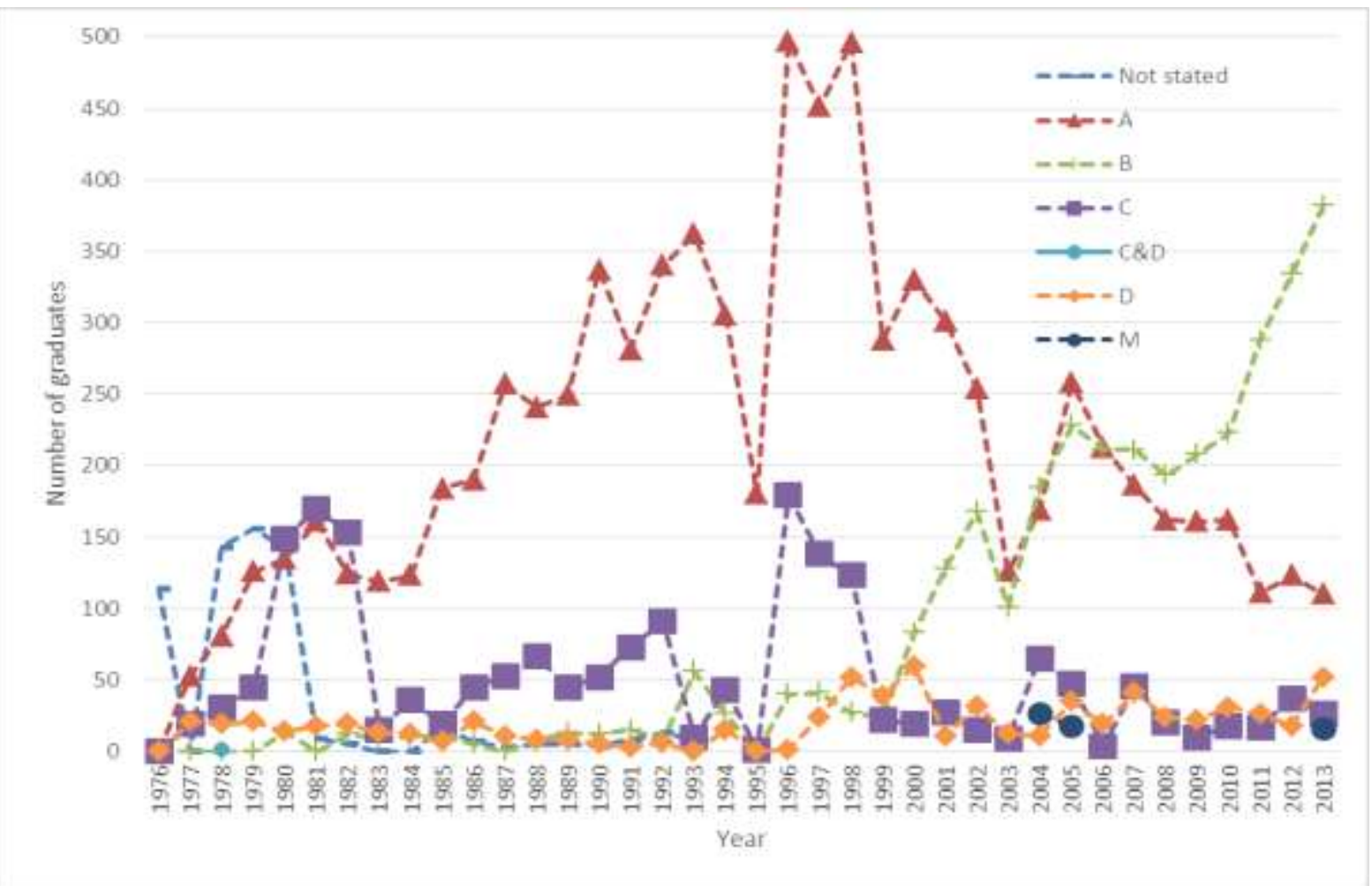

Figure 2: The number of students graduating at the end of each academic year by degree.

Key: A: Associate degrees, B: Baccalaureate degrees, C: Certificates, D: Diplomas, M: Masters degrees.

The growth and consolidation in the types of academic programmes offered by the College are demonstrated in Figure 3.

In 1977 three main offerings were available to students: associate degrees, certificates and diplomas. In that year 93 students graduated of which $57 \%$ graduated with associate degrees, $23 \%$ with diplomas and $20 \%$ certificates. Twelve years later in 1989, 320 students graduated, 227 more than 1977. By 1989 , the percentage of students graduating with associate degrees increased to $78 \%$.

The increase in the awarding of associate degrees was accompanied by a shrinking percentage of students graduating with diplomas and certificates. It is at this time that students graduating with baccalaureate degrees (4\%) start to be noticed. This is followed by a period of consolidation as the profile of graduates remains fairly constant until the early 2000's.

In 2001, 467 students graduated, an increase of $46 \%$ over 1989 . The number of students graduating with baccalaureate degrees increased by $23 \%$ over 1989; there was a decrease of $13 \%$ of students graduating with associate degrees. By 2013586 students graduated, an increase of $25 \%$ over 2001. In the graduating group, 3\% had master's degrees, $65 \%$ baccalaureate degrees and $19 \%$ associate degrees, which is a stark contrast to the profile just 12 years earlier in 2001 . 


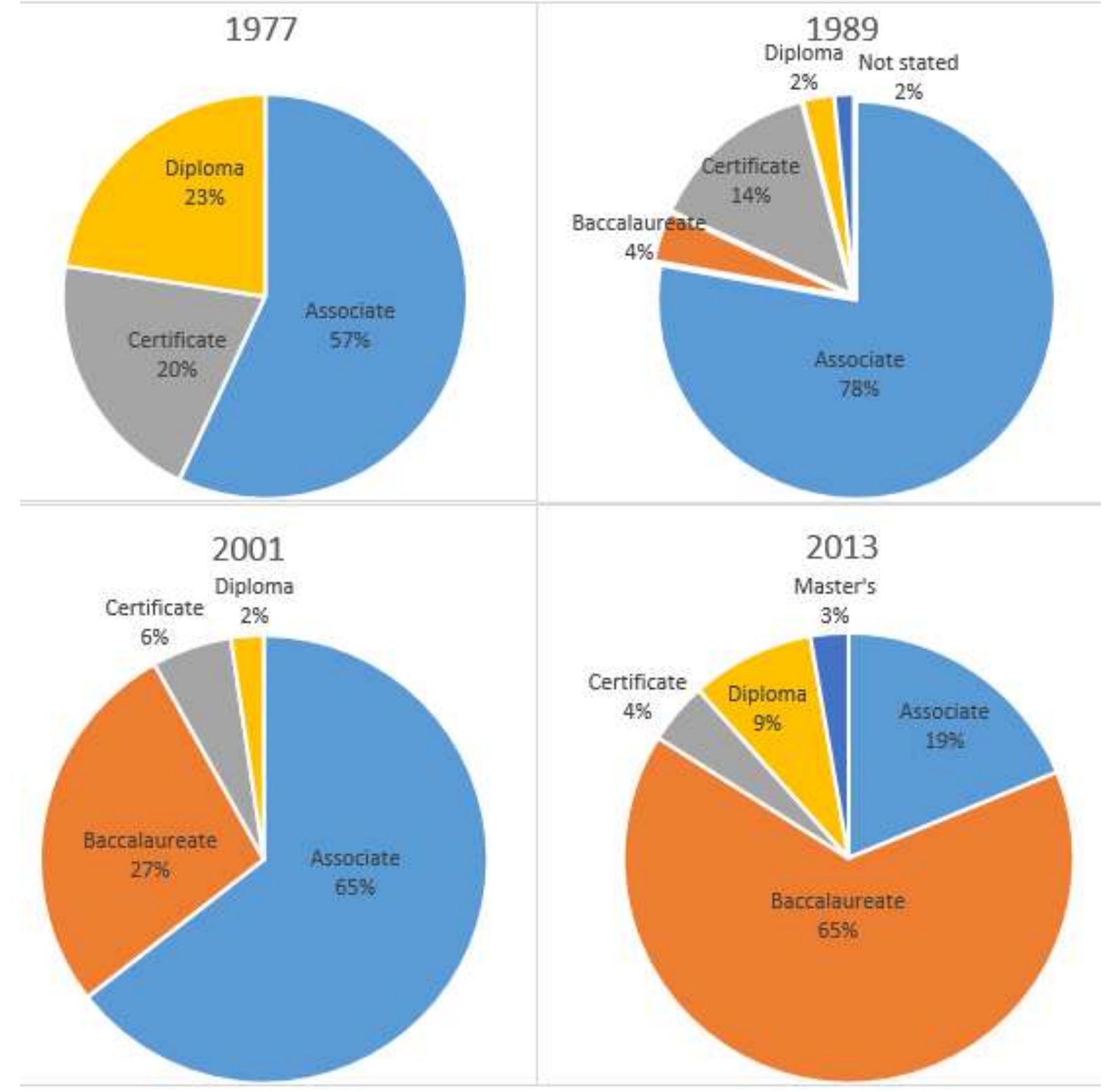

Figure 3: Profile of graduating student by degree.

\section{Discussion}

The profile of graduates allows us to illustrate the growth of the College from a community college-orientated institution to one that now looks very much like a university. With about two thirds of the graduates now receiving at least a baccalaureate degree, the College can be considered a university-level institution. The 2013 graduating class was the first to include post-graduate degrees using a College of The Bahamas curriculum. This paves the way for the College to embark upon its own Ph.D programmes. Overall, the changes in the graduate profile represent an unambiguous path towards university status. The offering of College of The Bahamas master's level programmes ultimately paves the way to doctoral degrees being offered. Doctoral programmes represent the apex of university teaching, and so their addition to the mix of College programmes can be expected to be the next goal of the institution. 